\title{
A LICITAÇÃO NAS EMPRESAS ESTATAIS
}

\author{
JosÉ CALASANS JUNIOR*
}

No ordenamento jurídico anterior a 1988, a obrigatoriedade da licitação tinha destinatários específicos: os órgãos da chamada administração direta e as autarquias. $\mathrm{Na}$ órbita federal, o Decreto-lei $\mathrm{n}^{0}$ 200, de 25 de fevereiro de 1967, que dispôs sobre a reforma administrativa federal, era explícito:

"Art. 125 - As licitações para compras, obras e serviços passam a reger-se, na Administração Direta e nas autarquias, pelas normas consubstanciadas neste Título e disposiçōes complementares aprovadas em decreto".

Essa disciplina veio a ser estendida aos Estados e Municípios pela Lei federal $\mathrm{n}^{0}$ 5.456, de 20 de junho de 1968, sob protesto de inconstitucionalidade.

Comentando a disposição desse Decreto-lei, HELY LOPES MEIRELLES era enfático em afirmar que as demais entidades vinculadas ao Poder Público, não enquadráveis como pessoas de direito público, não estavam submetidas às normas legais de licitação. Assim, não apenas as empresas públicas e sociedades de economia mista, como também os serviços sociais autônomos e as fundações instituídas pelo Poder Público estariam desobrigados da licitação formal. E esclarecia:

" $E$ justifica-se essa diversidade de tratamento porque as pessoas jurídicas de direito público estão sujeitas a normas de operatividade mais rígidas do que as pessoas jurídicas de direito privado, embora a serviço do Poder Público. Não se pode confundir a União, os Estados, os Municípios e suas autarquias, que operam em moldes estritamente públicos com as demais entidades que prestam serviços públicos ou realizam atividades de interesse público, mas em regime de direito privado (civil ou comercial). Para aquelas, a licitação é obrigatória; para estas, é facultativa." 1

Ainda sob o regime do Decreto-lei 200/67, não era diferente a opinião de CELSO ANTÔNIO BANDEIRA DE MELLO:

“18. União, Estados, Municípios, Distrito Federal, Territórios e autarquias estão obrigados a licitar em obediência às pertinentes leis de licitação o que é ponto

1 Licitação e Contrato Administrativo, Ed. Revista dos Tribunais, 5ª edição, pág. 79.

* Consultor Jurídico do Ministério de Minas e Energia.

R. Dir. Adm.,

Rio de Janeiro, 214: 107-114, out./dez. 1998 
incontroverso. O problema que se põe é saber se as sociedades de economia mista e empresas públicas também se assujeitam ao dever de licitar.

Parece-nos que ditas pessoas não podem se esquivar a um procedimento licitatório, salvo quando no exercicio de atos tipicamente comerciais ligados ao desempenho imediato de atividade industrial ou comercial que, por lei, thes incumba desenvolver como objeto das finalidades para que foram criadas.

Com efeito: entende-se que uma siderúrgica estatal compre rotineiramente, mediante os procedimentos usuais no mercado, as partidas necessárias para sua produção e que por iguais processos venda os seus produtos. Reversamente, se pretender equipar-se ou renovar seu equipamento produtor deverá atender aos princípios da licitação. Do mesmo modo, entende-se que uma indústria química, constituída sob forma de sociedade mista ou empresa pública, adquira, pelas formas correntes no meio empresarial que lhe corresponde, os produtos necessários à industrialização própria de seu mister e que comercialize sua produção por meios equivalentes aos utilizados pelas empresas privadas. Todavia, na aquisição dos equipamentos, do instrumental necessário, deverá acatar os princípios da licitação.

19. Note-se que não se está afirmando a sujeição de tais pessoas às específicas regras de licitação contempladas nos diplomas normativos pertinentes. Tal sujeição só ocorrerá quando a própria lei ou os estatutos da pessoa a estabelecerem ou, ainda, se a elas as entidades em causa se subordinarem por força de edital ou ato equivalente, ao ensejo de alguma aquisição ou alienação que se proponham a realizar.

O que se afirmou - coerentemente com as inúmeras manifestações que sempre expendemos ao respeito - é a submissão aos princípios da licitação (isonomia, publicidade, respeito às condições prefixadas, possibilidade do licitante fiscalizar $o$ atendimento aos principios anteriores)". ${ }^{2}$

Essa posição doutrinária não se modificou com o advento do Decreto-lei $\mathrm{n}^{\mathrm{o}}$ 2.300 , de 30 de novembro de 1986, editado com a finalidade específica de disciplinar a licitação pública. $\mathrm{O}$ art. 86 desse novo diploma legal estabelecia:

"As sociedades de economia mista, empresas e fundações públicas e demais entidades controladas direta ou indiretamente pela União, e pelas entidades referidas no artigo anterior, até que editem regulamentos próprios, devidamente publicados, com procedimentos seletivos simplificados e observância dos princípios básicos da licitação, inclusive as vedações contidas no parágrafo único do art. 85 , ficarão sujeitas às disposições deste Decreto-lei".

Essa nova prescrição legal deixou extreme de dúvida que as entidades estatais de direito privado estariam excluídas da incidência obrigatória das normas sobre licitação, desde que editassem e publicassem regulamentos próprios, "com procedimentos seletivos simplificados", submetendo-se, porém, aos "princípios básicos da licitação".

No entanto, a partir da edição da Lei $n^{9} 8.666$, de 21 de junho de 1993, restou inquestionável a submissão das empresas públicas e das sociedades de economia mista à licitação formal. Com efeito, ao atribuir à União competência privativa para 
legislar sobre "normas gerais de licitação e contratação, em todas as modalidades, para a administração pública", a Constituição de 1998 deixou claro que essas normas seriam aplicáveis "nas diversas esferas de governo, e empresas sob seu controle" (inciso XXVII do art. 22). Com base nessa determinação constitucional, a Lei 8.666/93 estabeleceu a submissão dessas entidades às suas normas, nestes termos:

"Subordinam-se ao regime desta lei, além dos órgãos da administração direta e fundos especiais, as autarquias, as fundações públicas, as empresas públicas, as sociedades de economia mista e demais entidades controladas direta ou indiretamente pela União, Estados, Distrito Federal e Municípios" (art. $1^{0}$, parágrafo único).

A meu ver, essa abrangência da Lei 8.666 não se compatibiliza com a Constituição. Sem pretender aprofundar a discussão da matéria, cabe, desde logo, deixar claro que essas entidades da chamada administração indireta, ou descentralizada, não podem ter o mesmo regramento dos órgãos públicos em geral. Especificamente em matéria de contratação, as empresas públicas e sociedades de economia mista devem ter garantida a flexibilidade de atuação que determinou a sua criação, pelo Poder Público.

Embora não compartilhasse do entendimento daqueles que desejavam ver as empresas estatais totalmente livres das normas da Lei 8.666, especialmente quando tais entidades exercem atividades econômicas, sempre defendi para elas uma disciplina mais flexível, que as submetesse aos princípios e normas gerais de toda a Administração Pública, mas lhes permitisse possuir regulamentos próprios, sem os rigores e formalismos que são impostos à Administração pública centralizada. Por isso, não posso aceitar como válida a disposição do art. 119 dessa lei, que impõe a essas entidades editar regulamentos próprios devidamente publicados, porém " $f i$ cando sujeitas às disposições desta Lei".

Tal disposição é contraditória e manifestamente inócua. De que adiantaria a uma empresa estatal editar regulamento próprio para suas licitações, se está sujeita, por completo, às disposições da Lei 8.666 ? O que poderia ser disciplinado nesse regulamento próprio, se todo o rito procedimental já está estabelecido, de forma inflexível, na lei geral?

Essa questão tem constituído motivo de sérios conflitos entre dirigentes de empresas estatais e órgãos de controle externo, sendo conhecida a posição dos Tribunais de Contas, no sentido de que as normas da Lei 8.666 são impositivas para todos os órgãos e entidades públicos, sem distinção, e de que alcançam as empresas estatais, independentemente de seu campo de atuação.

No entanto, na doutrina são conhecidas opiniōes mais tolerantes. CELSO ANTÔNIO BANDEIRA DE MELLO, já citado, defende a tese de que as empresas estatais que exploram atividades econômicas podem contratar sem licitação, quando ficar evidenciado que o procedimento compromete seu desempenho empresarial ou inviabiliza o atingimento de seus objetivos. Mesmo reconhecendo que a circunstância de estarem "sujeitas ao regime próprio das empresas privadas", consoante a regra do art. $173, \S 1^{9}$, da Constituição, não as exime da incidência do inciso XXI do art. 37 da mesma Carta Política, o mestre da Pontificia Universidade Católica de São Paulo afirma: 
"Com efeito, em inúmeros outros artigos da Constituição - como no art. 37, $X X I$, atinente à licitação - encontram-se normas que impõem a quaisquer entidades da Administração indireta ou fundacional regramento diverso do aplicável às empresas privadas, sem discriminar-se se são ou não exploradoras de atividade econômica. E em nenhum deles caberia duvidar de que também estas últimas estão abrangidas pelos sobreditos preceitos, conquanto as normas em questão lhes confiram tratamento distinto do que se aplica às empresas privadas. Assim, também, não há por pretender que o art. 37, XXI, esbarre no art. 173, $\S I^{Q}$.

Entretanto, será forçoso reconhecer que em inúmeros casos a licitação será incompativel com o normal cumprimento do escopo em vista do qual foram criadas (as empresas estatais). Ora, quem quer os fins não pode negar os indispensáveis meios. Logo, nestas hipóteses em que o procedimento licitatório inviabiliza o desempenho das atividades específicas para as quais foi constituida a entidade entender-se-á inexigivel a licitação. Isso ocorre quando suas aquisições ou alienações digam respeito ao desempenho de atos tipicamente comerciais, correspondentes ao próprio objetivo a que a pessoa está proposta e desde que tais atos demandem a agilidade, a rapidez, o procedimento expedito da vida negocial corrente, sem o que haveria comprometimento da boa realização de sua finalidade.

Fora desses casos, entretanto, o dever de licitar se impõe e é evidente nas hipóteses em que a entidade apenas está adquirindo, montando, reformando ou alienando suas instalações ou equipamentos, sem que, em tais operações, haja a interferência de qualquer peculiaridade relacionada com as exigências da atividade negocial que lhes é pertinente" 3 .

Já o Prof. MARÇAL JUSTEN FILHO ${ }^{4}$, da Universidade do Paraná, é incisivo em afirmar que a circunstância de uma empresa estatal explorar atividade econômica não a exime das normas gerais da Lei 8.666, isso porque — diz ele - " $O$ regime de direito privado se aplica exclusivamente aos contratos. Nāo há fundamento para afastar a incidência das regras ḋa Lei acerca de licitação. Mesmo as entidades que explorem atividades econômicas se sujeitarão às normas gerais sobre licitação. A aplicação dessas normas não é afetada pelos princípios da isonomia e da livre concorrência".

Agora, porém, penso que esse entendimento já não pode ser sustentado. É que a recente Emenda Constitucional $\mathrm{n}^{\mathrm{O}}$ 19, promulgada em junho de 1998, estabeleceu nova disciplina para a matéria. De fato, ao dispor sobre os "princípios e normas da Administração Pública, servidores e agentes políticos, controle de despesas e finanças públicas e custeio de atividades a cargo do Distrito Federal, e dá outras providências", a Emenda $19 / 98$ deu aos art. 22, inciso XXVII, e 173, § 1², da Constituição, nova redação, nestes termos:

“Art. 22. Compete privativamente à União legislar sobre:

3 Curso de Direito Administrativo - Malheiros Editores - 9^ edição, 1997, pág. 340.

4 Comentários à Lei de Licitaçōes e Contratos Administrativos - $4^{\mathrm{a}}$ edição - Aide Editora, pág. 18. 
XXVII - normas gerais de licitação e contratação, em todas as modalidades, para as administrações públicas diretas, autárquicas e fundacionais da União, Estados, Distrito Federal e Municípios, obedecido o disposto no art. 37, XXI, e para as empresas públicas e sociedades de economia mista, nos termos do art. $173, \S 1^{Q}$, III".

"Art. 173

$\S 1^{2} \mathrm{~A}$ lei estabelecerá o estatuto jurídico da empresa pública, da sociedade de economia mista e de suas subsidiárias que explorem atividade econômica de produção ou comercialização de bens ou de prestação de serviços, dispondo sobre:

I - sua função social e formas de fiscalização pelo Estado e pela sociedade;

II - a sujeição ao regime jurídico próprio das empresas privadas, inclusive quanto aos direitos e obrigações civis, comerciais, trabalhistas e tributários;

III - licitação e contratação de obras, serviços e alienações, observados os princípios da administração pública;

IV - a constituição e o funcionamento dos conselhos de administração e fiscal, com a participaçāo de acionistas minoritários;

$V$ - os mandatos, a avaliação de desempenho e a responsabilidade dos administradores".

Dessas duas novas disposições resulta clara a intenção do constituinte derivado no sentido de que: a) a lei que estabelecer o estatuto das empresas públicas e sociedades de economia mista deverá assegurar-lhes a sujeição exclusiva "ao regime jurídico próprio das empresas privadas, inclusive quanto aos direitos e obrigações civis, comerciais, trabalhistas e tributários"; b) as normas que essa lei estabelecer para a licitação e contratação das obras, serviços e alienações dessas empresas deverão levar em conta, apenas, "os princípios da administração pública".

Diante de termos tão claros e incisos, não vejo como se possa sustentar, ainda, a incidência da Lei 8.666 sobre as licitações das empresas estatais, sejam elas exploradas de atividade econômica, ou prestadoras de serviços. Não compreendo, portanto, a opinião manifestada pelo Prof. MARÇAL JUSTEN FILHO, que indagado sobre como fica a atuação das empresas públicas e sociedades de economia mista, no que tange às contratações, em face da reforma administrativa decorrente da mencionada Emenda n 19/98, afirmou:

"Rigorosamente, a EC n 19 não trouxe qualquer modificação efetiva nesse ponto. É que a alteração da redação do art. 22, inc. XXVII, da CF/88 não foi suficiente para estabelecer um regime especial para sociedades de economia mista e empresas públicas. Aliás, a modificação do texto constitucional foi inútil nesse ponto. Não era necessário modificar a Constituição para dar um novo regime para licitações e contratos daquelas entidades. Bastava mudar a Lei de Licitações. Mas ainda, sem mudar a Lei de Licitaçōes atual, não há como alterar o regime jurídico a que elas se subordinam. Há outra questão que deve ser destacada. Há, no mínimo, duas espécies de sociedades de economia mista e empresas públicas. Existem as que exercem atividade econômica e estâo disciplinadas pelo art. $173, \S I^{o}$, da CF/88. Mas também há os do art. 175, que desempenham serviços públicos. A EC $n^{Q} 19$ não se referiu a estas últimas. Resta determinar, por isso, se elas se sujeitam às 
regras próprias da iniciativa privada ou ao regime de direito público próprio da Administração direta". 5

Destaques e grifos postos.

Com todo o respeito, penso que a essa afirmativa incide em dois equívocos. $O$ primeiro, é o de supor que as "normas gerais" da Lei 8.666 equivalem aos "princípios da administração pública", a que se refere o inciso III do novo art. $173, \S 1^{\circ}$. À parte a discussão sobre o que se deva entender por normas gerais, no que não há dúvida é quanto à impossibilidade de se considerar como tais as regras de procedimento, minudentes e detalhistas, que a Lei 8.666 ditou, de forma autoritária e abrangente, para todos os órgãos e entidades públicos das três esferas de governo. $\mathrm{O}$ segundo equívoco, é o de admitir que uma sociedade de economia mista, ou uma empresa pública, possa estar submetida, por inteiro, ao regime de direito público apenas porque presta serviços públicos. O texto do $\S 1^{0}$ do art. 173 é expresso ao se referir às empresas públicas, sociedades de economia mista e suas subsidiárias "que explorem atividades econômica de produção ou comercialização de bens ou de serviços". O dispositivo não fala em "serviços públicos", logo, não cabe ao intérprete ampliar a norma, ou distinguir onde o texto não distingue.

Indiscutivelmente, agora todas as empresas públicas e as sociedades de economia mista, qualquer que seja seu objeto ou campo de atuação, sujeitam-se " ao regime jurídico próprio das empresas privadas, inclusive quanto aos direitos e obrigações civis, comerciais, trabalhistas e tributários".

Ouso afirmar, portanto, que desde a promulgação da Emenda no 19/98, a Lei 8.666 já não se aplica às empresas estatais. Até que seja editada a lei prevista no novo texto constitucional, somente os "princípios da administração pública", previstos nessa lei, que correspondam aos estabelecidos no art. 37 da Carta de 1988, são obrigatórios para as empresas públicas e sociedades de economia mista e suas subsidiárias. Entendo mais: essas empresas estatais podem, agora, editar seus regulamentos de licitação, com o procedimento que mais se ajuste aos seus objetivos e propósitos empresariais.

Foi o que fez a PETROBRÁS, com base em autorização específica, conferida pela Lei $\mathrm{n}^{\mathrm{O}}$ 9.478, de 6 de agosto de 1997, que regulamentou a flexibilização do monopólio do petróleo. Reconhecendo a necessidade de essa estatal atuar, doravante, em regime competitivo com as demais empresas da indústria do petróleo, a Lei 9.478 previu que as contratações de obras e serviços da PETROBRÁS deverão ser processadas segundo um procedimento licitatório simplificado, definido em decreto do Presidente da República. Como Consultor Jurídico do Ministério de Minas e Energia, fui responsável pela elaboração desse regulamento, que foi aprovado pelo Decreto $\mathrm{n}^{\mathrm{o}} 2.745$, de 24 de agosto de 1998, publicado no Diário Oficial da União de 25 do mesmo mês, e assim defendi as inovações procedimentais nele inseridas:

12. Por outro lado, com o propósito de assegurar à empresa estatal competitividade e igualdade de condições perante os novos agentes econômicos que deverão

5 Informativo Licitações \& Contratos $n^{0} 54$ - Agosto/98 - Zênite - Informação e Consultoria em Administração Pública Ltda. 
atuar na indústria do petróleo, a Lei n. 9.478, de 1997, estabeleceu que "os contratos celebrados pela PETROBRÁS, para aquisição de bens e serviços, serão precedidos de procedimento licitatório simplificado, a ser definido em decreto do Presidente da República" (art. 67).

13. A disposição inscrita no mencionado artigo objetivou, também, explicitar o reconhecimetno da necessidade de que empresas estatais que desenvolvem atividades econômicas, como é o caso da PETROBRÁS, não devem estar submetidas às mesmas regras procedimentais de licitação que são impostas aos órgãos da administração direta, autárquica e fundacional.

14. É certo que, por força do que determinava o art. 22, inciso XXVII, da Constituição, também as empresas sob controle do Poder Público sujeitavam-se às normas gerais de licitação e contratação editadas por lei federal. Entretanto, a mesma Constituição era expressa no sentido de que "a empresa pública, a sociedade de economia mista e outras entidades que explorem atividades econômica sujeitam-se ao regime jurídico próprio das empresas privadas, inclusive quanto às obrigações trabalhistas e tributárias" (art. 173, $\S 1^{9}$ ).

15. Parecia evidente, portanto, que as empresas estatais, do tipo da PETROBRÁS, embora não possam, nem devam, eximir-se da obrigatoriedade da licitação, necessitam fazê-la de forma diferenciada, mais flexível e menos burocrática, sob pena de comprometer o próprio objetivo para o qual foram criadas pelo Poder Público.

16. Esse entendimento está, agora, contemplado pelo texto constitucional, a partir da Emenda $n^{2} 19$, promulgada no dia 4 de junho passado, que, além de outras alterações introduzidas com o propósito de modernizar e flexibilizar a Administração Pública, deu nova redação ao mencionado $\S 1^{\circ}$ do art. 173 do texto original da Carta de 1988, para determinar que o estatuto jurídico da empresa pública, da sociedade de economia mista e de suas subsidiárias que explorem atividade econômica de produção ou comercialização de bens ou de prestação de serviços, a ser estabelecido em lei específica, deverá dispor sobre "a sujeição ao regime jurídico próprio das empresas privadas, inclusive quanto aos direitos e obrigações civis, comerciais, trabalhistas e tributários" e sobre "licitação e contratação de obras, serviços, compras e alienações, observados os princípios da administração pública" (incisos II e III).

17. A previsão contida no art. 67 da Lei $n^{2} 9.478$, de 1997, está perfeitamente adequada ao propósito do novo texto constitucional, na medida em que, sem eximir a PETROBRÁS da obrigatoriedade de licitar a aquisição de bens e serviços, permite-lhe que o faça mediante procedimento simplificado.

18. Embora guardando afinidade com as normas básicas e gerais que tratam da licitação, o Regulamento que está sendo proposto conferirá à PETROBRÁS a flexibilidade de atuação indispensável para garantir-lhe competitividade e igualdade de oportunidades, frente aos demais agentes econômicos, no desenvolvimento das atividades vinculadas à indústria do petróleo" ${ }^{6}$

6 Parecer CONJUR/MME n² 068/98, de 04.08.98, que acompanhou a Exposiçāo de Motivos do Ministro de Minas e Energia com a qual foi encaminhado o projeto do Decreto. 
Embora mantendo a nomenclatura e a conceituação consagradas na lei geral e na doutrina sobre licitações, a característica marcante desse Regulamento é a simplificação do procedimento. Com esse propósito, destacam-se regras que consagram, por exemplo:

a) significativa redução dos prazos de publicação dos editais (30 dias para as concorrências e 15 para as tomadas de preços), permitindo-se que a Diretoria da Empresa, por decisão justificada, possa encurtá-los para 20 e 10 dias, respectivamente;

b) definição de critérios mais objetivos e simples para avaliação e classificação das propostas, com a eliminação da atribuição de notas (nas licitações de técnica considerar-se-ão classificadas todas as propostas que atenderem às especificações e requisitos do ato convocatório, declarando-se vencedora a que oferecer o melhor preço);

c) obrigatoriedade de a Comissão avaliar todos os aspectos e fatores, previamente estabelecidos no ato convocatório, que possam proporcionar maior vantagem para a PETROBRÁS, qualquer que seja o tipo da licitação;

d) conceituação mais adequada dos tipos de licitação, substituindo-se o "menor preço" pelo "melhor preço", assim considerado aquele que implique menor dispêndio para a PETROBRÁS;

e) fixação dos prazos para recursos em dias corridos;

f) limitação do efeito do recurso à licitante ou proposta afetada. Diferentemente do que ocorre no regime da Lei 8.666/93, a impugnação ou recurso contra uma licitante ou proposta não impedirá que a Comissão dê seguimento ao processo, relativamente às demais licitantes ou propostas, não podendo, é óbvio, passar à fase seguinte do procedimento, senão depois de decidir a impugnação ou recurso;

g) possibilidade de negociação com a vencedora, com vistas a redução do valor da proposta.

Agora, fazer licitação não constituirá obstáculo aos objetivos empresariais da PETROBRÁS, tampouco comprometerá a sua competividade, frente às demais empresas privadas do setor de sua atuação.

Quanto aos contratos, o Regulamento os define como submetidos exclusivamente ao direito privado, portanto, baseados no princípio da autonomia da vontade das partes. Ao mesmo tempo, numa inovação que já deveria ter sido contemplada na Lei de Licitações, o Regulamento prevê que os contratos conterão, sempre, cláusulas que assegure à PETROBRÁS o direito de, mediante retenção de pagamentos, ressarcir-se de quantias que lhe sejam devidas pela firma contratada, quaisquer que sejam a natureza e origem desses débitos.

Estou convencido de que o caminho de abertura da Lei 9.478 será seguido pela lei que definir o estatuto jurídico das empresas públicas e sociedades de economia mista, na impedindo que, antes da edição dessa lei, outras empresas estatais elaborem e publiquem regulamentos próprios, similares ao da PETROBRÁS, para disciplinar suas licitações e contratos de forma compatível com seus objetivos empresariais, sobordinando-se, exclusivamente, aos princípios da administração pública, como determina o novo texto constitucional. 